\title{
Comparison of a prepositioned areal electrofishing device and fixed underwater videography for sampling riverine fishes
}

\author{
Philip R. Branigan $1,5, *$, Michael C. Quist ${ }^{2}$, Bradley B. Shepard ${ }^{3}$, and Susan C. Ireland 4 \\ ${ }^{1}$ Idaho Cooperative Fish and Wildife Research Unit, University of Idaho, 875 Perimeter Dr. MS 1141, Moscow, ID 83844 \\ ${ }_{2}^{2}$ U.S. Geological Survey, Idaho Cooperative Fish and Wildlife Research Unit, \\ University of Idaho, 875 Perimeter Dr. MS 1141, Moscow, ID 83844 \\ ${ }^{3}$ B.B. Shepard and Associates, 659 th Street Island Dr., Livingston, MT 59047 \\ ${ }^{4}$ Kootenai Tribe of Idaho, Box 1269, Bonners Ferry, ID 83805 \\ ${ }^{5}$ Present address: Idaho Department of Fish and Game, 1414 E. Locust Ln., Nampa, ID 83686
}

\begin{abstract}
Prepositioned areal electrofishing devices (PAEDs) are used to evaluate microhabitat use by fishes because they minimize fright biases associated with traditional electrofishing techniques (e.g., boat electrofishing). Similarly, fixed underwater videography (FUV) is commonly used to minimize the effect of observers on fish behavior. The specific objectives of this research were to evaluate estimates of taxonomic occurrence and diversity between PAEDs and FUV and determine an appropriate time interval between positioning and electrifying of a PAED to reduce effects of PAED positioning on fish occurrence. Video cameras were positioned instream at 28 locations on the Kootenai River, Idaho, prior to PAED deployment such that the entire immobilization zone of the PAED was captured on camera. Following a 4-min acclimation period, cameras recorded fish behavior approximately 15 min prior to and 20 min following PAED deployment. Electrical current was applied to the PAEDs for $20 \mathrm{~s}$ immediately following the FUV procedure, and immobilized fishes were collected and processed. Video footage was subsampled in the laboratory, and fishes in the video were identified and enumerated in 5-s or 20-s intervals. Fixed underwater videography sampled more taxa than PAEDs at any given site. However, fishes sampled with FUV were difficult to identify, and most individuals were classified as "unidentifiable." Consequently, direct comparisons between FUV and PAEDs are limited. Our results indicate that PAEDs should remain undisturbed for a minimum of $12 \mathrm{~min}$ before the equipment is electrified. Both PAEDs and FUV provide an estimate of taxonomic occurrence, but logistical and financial constraints along with project objectives must be considered when selecting between these 2 gear types. Results from this study provide information on the effectiveness of each gear type as it relates to the characterization of riverine fish assemblages at a small spatial scale.
\end{abstract}

RESUMEn.-Los dispositivos de electropesca para áreas preposicionadas (PAED, por sus siglas en inglés) se utilizan para evaluar el uso que los peces hacen de los microhábitats, dado que minimizan la tendencia de los peces a huir asociada a las técnicas tradicionales de electropesca (e.g., embarcaciones de electropesca). De manera similar, la videografía submarina fija (FUV, por sus siglas en inglés) se utiliza, comúnmente, para minimizar el impacto de los observadores sobre el comportamiento de los peces. Los objetivos específicos de esta investigación fueron comparar los estimados obtenidos de presencia taxonómica y diversidad de los PAED y la FUV, y determinar un intervalo de tiempo apropiado entre la colocación y el electrificado de los PAED, que reduzca el efecto de la instalación de los PAED en la presencia de peces. Las cámaras de video se colocaron en 28 sitios dentro del río Kootenai, Idaho, previo a la instalación de los PAED, de tal forma que la cámara pudiera captar toda la zona de inmovilización de los PAED. Luego de un período de aclimatación de cuatro minutos, las cámaras registraron el comportamiento de los peces aproximadamente 15 minutos antes y 20 minutos después de la implementación de los PAED. Se aplicó corriente eléctrica a los PAED durante 20 segundos e inmediatamente después el procedimiento de la FUV, y se recogieron y procesaron los peces inmovilizados. El archivo de video fue submuestreado en el laboratorio, donde los peces fueron identificados y enumerados en intervalos de 5 a 20 segundos. La videografía submarina fija muestreó mayor cantidad de taxa que los PAED en cualquier sitio. Sin embargo, los peces muestreados con FUV fueron difíciles de identificar, siendo la mayoría clasificados como "no identificables". Por lo tanto, las comparaciones directas entre las FUV y los PAED son limitadas. Nuestros resultados indican que los PAED deben permanecer intactos durante un mínimo de 12 minutos antes de electrificar el equipo. Tanto los PAED como las FUV proporcionan un estimado de presencia taxonómica. Sin embargo, las limitaciones logísticas y financieras, junto con los objetivos del proyecto deben ser considerados al elegir entre estos dos tipos de dispositivos. Los resultados de este estudio proporcionan información sobre la eficacia de cada tipo de dispositivo en lo que respecta a la caracterización de conjuntos de peces ribereños en una escala espacial pequeña.

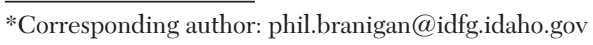

orcid.org/0000-0003-3799-0573 
Understanding the relationship between fishes and their environment has long been an important focus of fish scientists (Rosenfeld 2003, Fisher et al. 2012). Resource use and partitioning by lotic fishes regulate the structure of fish assemblages, particularly at small spatial scales (Gorman and Karr 1978, Ross 1986). Aquatic habitats are often considered within the context of a hierarchy, where upperlevel processes occur over long temporal and large spatial scales (e.g., a watershed) and lowerlevel processes occur over shorter temporal and smaller spatial scales (e.g., channel units; Quist et al. 2005). Microhabitat data are an integral component of this hierarchy because they reflect specific habitat conditions (e.g., depths, current velocities) selected by stream fishes and can be used to understand habitat requirements and distributions of fishes.

Reductions in habitat quality and quantity have been identified as primary factors that contribute to declining freshwater fauna populations across North America (Ricciardi and Rasmussen 1999). Large rivers have been extensively modified by water development (e.g., dams, levees, diversions) to serve societal needs (e.g., power generation, flood control, navigational routes; Nilsson et al. 2005, Dudgeon et al. 2006). In an effort to mitigate habitat degradation, natural resource and conservation agencies have implemented over 37,000 habitat improvement projects on rivers and streams in the United States (Bernhardt et al. 2005). Habitat improvement programs lead to species recovery, particularly by enhancing instream habitat or by reconnecting isolated habitats (Roni et al. 2008). An integral component of the habitat improvement process is to establish a monitoring program that can effectively evaluate the response of the fish assemblage to improvements (Kondolf and Micheli 1995, Palmer et al. 2005). Unfortunately, many monitoring programs have focused on the physical responses to instream habitat improvements and have neglected to thoroughly address the biological responses (Roni et al. 2002). Arguably, assessing the biological response to habitat improvement is perhaps the best measure of effectiveness, and obtaining an accurate measure of the response elicited by fishes starts by selecting suitable sampling equipment.

Quantifying microhabitat use by fishes requires careful selection of an appropriate sampling gear. A variety of gears have been used to sample riverine fishes (e.g., seines, gill nets, electrofishing, snorkeling; Bonar et al. 2009). Electrofishing is generally considered the most effective gear type for sampling coldwater fishes in rivers because it minimizes the mortality, injury, and size selectivity that are often associated with other gears (e.g., gill nets and hoop nets; Curry et al. 2009). However, active electrofishing techniques (i.e., boat or backpack electrofishing) are conducted by personnel who maneuver the electrodes through the water and the resulting disturbance can drive fish from their original location ("fright bias"; Bovee 1982). Because microhabitat use occurs at a small scale, precautionary measures must be taken to sample fishes from their naturally selected habitats and not from habitats used in response to sampling.

To reduce the influence of fright bias, prepositioned areal electrofishing devices (PAEDs) are often used to sample fishes when evaluating microhabitat use (Bain et al. 1985, Reynolds and Kolz 2012, Dauwalter et al. 2014). Prepositioned areal electrofishing devices use fixed electrodes that are deployed prior to the sampling event and remain undisturbed for a period of time. After an allotted amount of time has passed (commonly referred to as the PAED "set time"), current is applied and the fish are immobilized. Typically, the design of a PAED is relatively inconspicuous compared to other passive sampling gears (e.g., hoop nets and trap nets), thereby minimizing the effect of gear avoidance or attraction by fishes. Additionally, PAEDs sample a discrete area, allowing the investigator to quantify habitat characteristics that reflect those selected by fishes at a small scale. An important assumption when using PAEDs is that fish return to the sampling area following the initial disturbance associated with deploying the gear.

Direct observation techniques are commonly used to characterize fish assemblages in natural environments (Thurow et al. 2012). Direct observation methods have been used to evaluate fish distribution and abundance (Hankin and Reeves 1988), population size structure (Griffith 1981), and habitat use (Fausch and White 1981, Bozek and Rahel 1991). Snorkeling is one of the most common and simplest ways to observe fish and requires minimal equipment. In general, snorkeling 
can be effective in a variety of habitats, but environmental conditions and differences in ability, training, and experience among personnel can bias results (Thurow et al. 2012). Moreover, the presence of human observers during snorkeling events has been shown to elicit a flight response by fish (e.g., Peterson et al. 2005). Thus, remote methods of direct observation (e.g., cameras) have been developed to reduce the influence of human presence during direct observation procedures.

Similar to PAEDs, fixed underwater videography (FUV) can be used to sample a discrete area and serves to decrease fright bias. Underwater videography has been used to quantify fish density (Willis and Babcock 2000), abundance (Ellis and DeMartini 1995, Stoner et al. 2008), species richness (Ebner and Morgan 2013), and habitat use (Becker et al. 2010). However, FUV is most commonly applied to studies of fish behavior (e.g., Suzuki et al. 2003, Kane et al. 2004, Ebner et al. 2009). Most recently, underwater video has been used to sample fish in areas where other gears fail (e.g., dense aquatic vegetation; Wilson et al. 2015). Recent advancements in technology have provided consumers with inexpensive video cameras that are capable of capturing high-quality underwater video footage. Previous studies have incorporated FUV techniques with and without bait (e.g., Stobart et al. 2007, Hannah and Blume 2012), but many of those studies were conducted in marine environments or coral reef systems and used large, conspicuous video lander systems (e.g., Ellis and DeMartini 1995, Willis and Babcock 2000, Stobart et al. 2007). Using cameras outfitted with bait tends to provide samples with increased fish counts, but the increase in sample size comes as a result of attracting fishes to the gear (Watson et al. 2005, Harvey et al. 2007). Thus, the concept of sampling fishes from naturally selected habitats is negated.

In the current study, we evaluated the efficacy of a PAED and FUV for sampling fishes in riverine environments. In addition, we sought to determine an appropriate "set time" (i.e., elapsed time between electrode deployment and electrification) for sampling riverine fishes with a PAED. We empirically assessed the relative abundance of fishes prior to and following electrode deployment using FUV techniques. The deployment sequences for PAEDs and FUV are nearly identical; both sampling techniques disturb the intended sampling area for a similar amount of time and require that the area remain undisturbed following deployment of the gear. We postulated that FUV may be used to sample riverine fishes with equal accuracy relative to PAED samples while minimizing bias due to gear or observers.

\section{Methods \\ Study Area}

The Kootenai River (spelled Kootenay in Canada) has an international and interstate watershed that receives up to $3000 \mathrm{~mm}$ of precipitation annually and drains an area of approximately $49,987 \mathrm{~km}^{2}$ (Woods 1982 , Knudson 1994). The river originates in Kootenay National Park, British Columbia, Canada, at an elevation of $3618 \mathrm{~m}$ and flows for $775 \mathrm{~km}$. From British Columbia, the river flows southward into Montana, USA, where it is impounded by Libby Dam, which forms Lake Koocanusa. From Libby Dam, the river flows northwest into the panhandle of Idaho, USA, then north into British Columbia where it enters Kootenay Lake before joining the Columbia River near Castlegar, British Columbia, at an elevation of $418 \mathrm{~m}$. The Kootenai River is the second largest tributary to the Columbia River in terms of runoff volume and third largest in drainage area (Knudson 1994).

In Idaho, the Kootenai River is categorized into 3 distinct sections based on unique geomorphologies: canyon, braided, and meander (Smith et al. 2016). The canyon section has high current velocities, large substrate (e.g., cobble, boulder), a restricted floodplain, and is characterized by the occurrence of native salmonids (rainbow trout Oncorhynchus mykiss and mountain whitefish Prosopium williamsoni; Smith et al. 2016). The braided section is a transitional zone that has high rates of sediment deposition, a low gradient, a wide valley with prominent floodplain, a braided channel type, and is characterized by the occurrence of native salmonids, catostomids (largescale sucker Catostomus macrocheilus), and redside shiner Richardsonius balteatus. The meander section has low current velocities, a low gradient, a single, sinuous channel, and is characterized by the occurrence of cyprinids (northern pikeminnow Ptychocheilus oregonensis and peamouth Mylocheilus caurinus). 
The braided section has the highest level of habitat complexity and dynamism compared to the canyon and meander sections (Smith et al. 2016). Consequently, the braided section has the highest species richness estimate relative to the canyon and meander sections. As such, the braided section has been the primary focus of a large-scale and long-term habitat rehabilitation program that aims to enhance existing habitat for the benefit of native fishes at all life history stages (KTOI 2009, Watkins et al. 2015). The objectives of the habitat rehabilitation program are numerous, but some of the primary projects include treatments designed to disperse flow, create floodplain habitat, increase substrate heterogeneity, and create complex in-water habitats by adding woody structures.

\section{Field Sampling}

Sampling occurred during daylight hours in wadeable areas of the braided section of the Kootenai River, Idaho, in August 2014. Twenty-eight sites were randomly selected to receive sampling effort using FUV and PAEDs. Microhabitat characteristics differed across sites; current velocities varied from 0.00 to $1.06 \mathrm{~m} / \mathrm{s}$, depths varied between 0.12 and $1.10 \mathrm{~m}$, and substrate size varied from sand $(>0.07 \mathrm{~mm})$ to boulder $(>257.00 \mathrm{~mm})$. Electrodes were deployed in pairs consisting of a cathode and anode that collectively constituted a PAED. Each electrode was constructed with a 9.1-m length of insulated, tinned-copper wire that terminated in a plug (Midwest Lakes Electrofishing Systems; Polo, MO). The insulated wire articulated with a length of 4.8-mmdiameter stainless steel aircraft (SSA) cable that remained exposed and served as the conducting material for closure of the electrical circuit. The cathode was constructed using $6.1 \mathrm{~m}$ of SSA cable, and the anode used $3.4 \mathrm{~m}$. A wire rope clip was used to secure a loop for the anode, producing a circular ring (area $=$ $0.80 \mathrm{~m}^{2}$ ). We positioned the cathode approximately $1 \mathrm{~m}$ downstream from the anode perimeter to ensure consistent electrical fields among sampling locations. The electrodes were powered by applying pulsed direct current standardized to 500-800 W using a LR-24 backpack electrofisher (Smith-Root Inc., Vancouver, WA) retrofitted to accept the terminal plugs on the PAED. Given the physical properties of pulsed direct current, fishes were immobilized beyond the confines of the anode. Pilot studies indicated that the immobilization zone of the PAED was approximately $4 \mathrm{~m}^{2}$.

Video footage was collected using a GoPro Hero3 $+{ }^{\circledR}$ camera (GoPro, Inc., San Mateo, CA). The camera was housed in a black underwater casing mounted to a metal stake, and it collected footage at a rate of 30 frames per second. The camera was positioned instream such that the entire immobilization zone of the PAED was included in the field of view (area of approximately $4 \mathrm{~m}^{2}$ ). A sampling event occurred in 3 phases (Fig. 1). First, a video camera was positioned instream and collected 15-20 min of footage (T1, "baseline" footage). Second, a PAED was positioned approximately $0.50 \mathrm{~m}$ in front of the camera and was oriented perpendicular to the thalweg while video footage continued to be recorded. The area remained undisturbed for an additional 15-35 min following PAED deployment (T2, "set" footage). Third, the PAED was electrified for $20 \mathrm{~s}$ and a single netter entered the water and collected immobilized fishes (T3). Fishes were identified, enumerated, measured (total length), and returned to the water. Baseline and set times used in this study were motivated by the results of Bain et al. (1985). The authors found no significant correlation between PAED set time and number of fish captured $(P=0.43$; Bain et al. 1985) and noted that a set time of $10 \mathrm{~min}$ was adequate for their study. We chose a longer set time to (1) account for instances where 10 min may not have provided enough time for fishes to return and (2) strike a balance with video processing time. Electrical current was applied to the PAEDs for $20 \mathrm{~s}$ to standardize electrofishing effort across sites. This time period provided enough time for personnel to enter the water and collect immobilized individuals while minimizing undue stress to the fish.

\section{Video Processing}

Video footage was processed using VLC Media Player (VideoLan Team) and viewed in real time on a computer monitor. Video footage was systematically subsampled in 5-s increments to minimize the chance of missing the return of a taxon to the sample area. A single observer enumerated and identified fishes. For instances when high fish density made enumeration difficult, 2 observers reviewed the video in 20-s increments and determined 


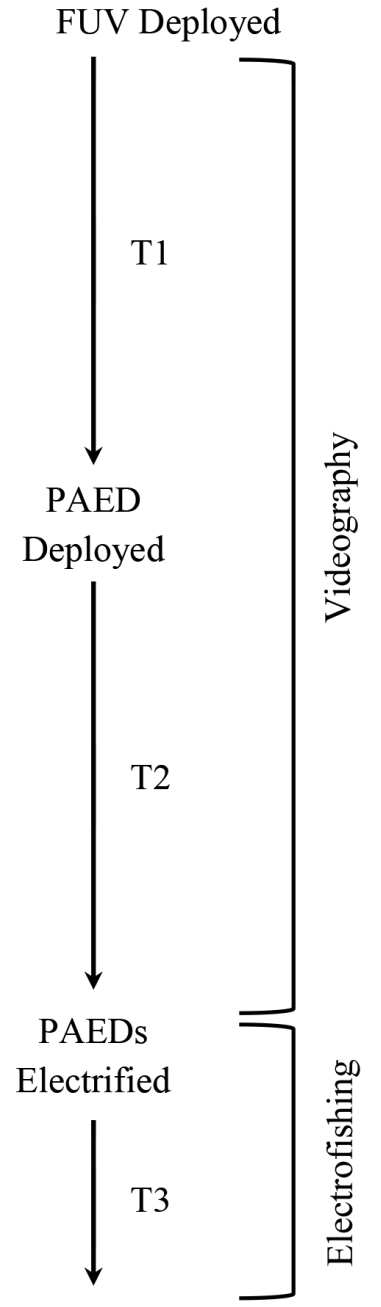

Fig. 1. Representation of the continuous field sampling procedure that occurred in 3 distinct phases. Time period one (T1) represents the elapsed time between fixed underwater videography (FUV) and prepositioned areal electrofishing device (PAED) deployment (i.e., "baseline" footage). Time period two (T2) represents the elapsed time between the PAED deployment and electrification (i.e., PAED "set" footage). Time period three (T3) represents the time during which electricity was applied to the PAED (20 s).

a final count by consensus. Fishes were identified to the lowest possible taxonomic level. If identification of a particular fish could not be determined, the individual was recorded as "unidentifiable." Multiple viewings of footage were necessary in certain situations (e.g., high fish density, presence of small fishes, poor underwater visibility) to ensure accurate identification and counts.
Data Analysis

Subsamples from the first $4 \mathrm{~min}$ of video footage were omitted from the analysis. This period was based on an evaluation of fish response to positioning the camera instream. Similar acclimation periods for FUV studies have been reported (Frezza et al. 2003, Harvey et al. 2007). Count data were summarized by gear type to estimate taxonomic occurrence and relative abundance. Fish counts for FUV data were summarized by estimating the frequency of occurrence divided by the number of subsamples from each video time period (i.e., T1 and T2). Fish count data obtained with PAEDs (i.e., T3) provided a measure of taxonomic occurrence that served as a baseline against which to compare FUV data. As such, care was taken to avoid frightening additional fish into the electrical field while also capturing every immobilized fish. Relative abundance estimates for FUV data were calculated using a modified MaxN index following Ellis and DeMartini (1995). Specifically, MaxN is the maximum number of individuals for any taxa present in the field of view at the same time. This approach reduces the chance of counting the same fish more than once (Becker et al. 2010, Ellender et al. 2012). Since our subsampling procedure enumerated fish at relatively short time intervals, we estimated MaxN for each minute of video footage by selecting the maximum MaxN among the subsamples in a minute of video. Maximum MaxN was averaged across all minutes and time periods (i.e., T1, T2, T3) at each site to calculate a mean MaxN $(\operatorname{mMaxN})$ value for each identified taxon. Mean MaxN values were then averaged across all sites to estimate the mean mMaxN value for each identified taxon.

To evaluate the efficacy of the FUV approach, we compared occurrence and total relative abundance estimates from PAEDs with those from FUV over the integrated time period of $\mathrm{T} 1, \mathrm{~T} 2$, and $\mathrm{T} 3$. A paired Wilcoxon signed-rank test was applied to the relative abundance data from $\mathrm{T} 1$ and $\mathrm{T} 2$ to evaluate the effect of the PAED on the fish assemblage. To determine an appropriate PAED set time, we measured the length of time until fishes returned to the sample area following PAED deployment. Taxon-specific return times were averaged across all sites, and a suggested PAED set time was determined by averaging those values. 


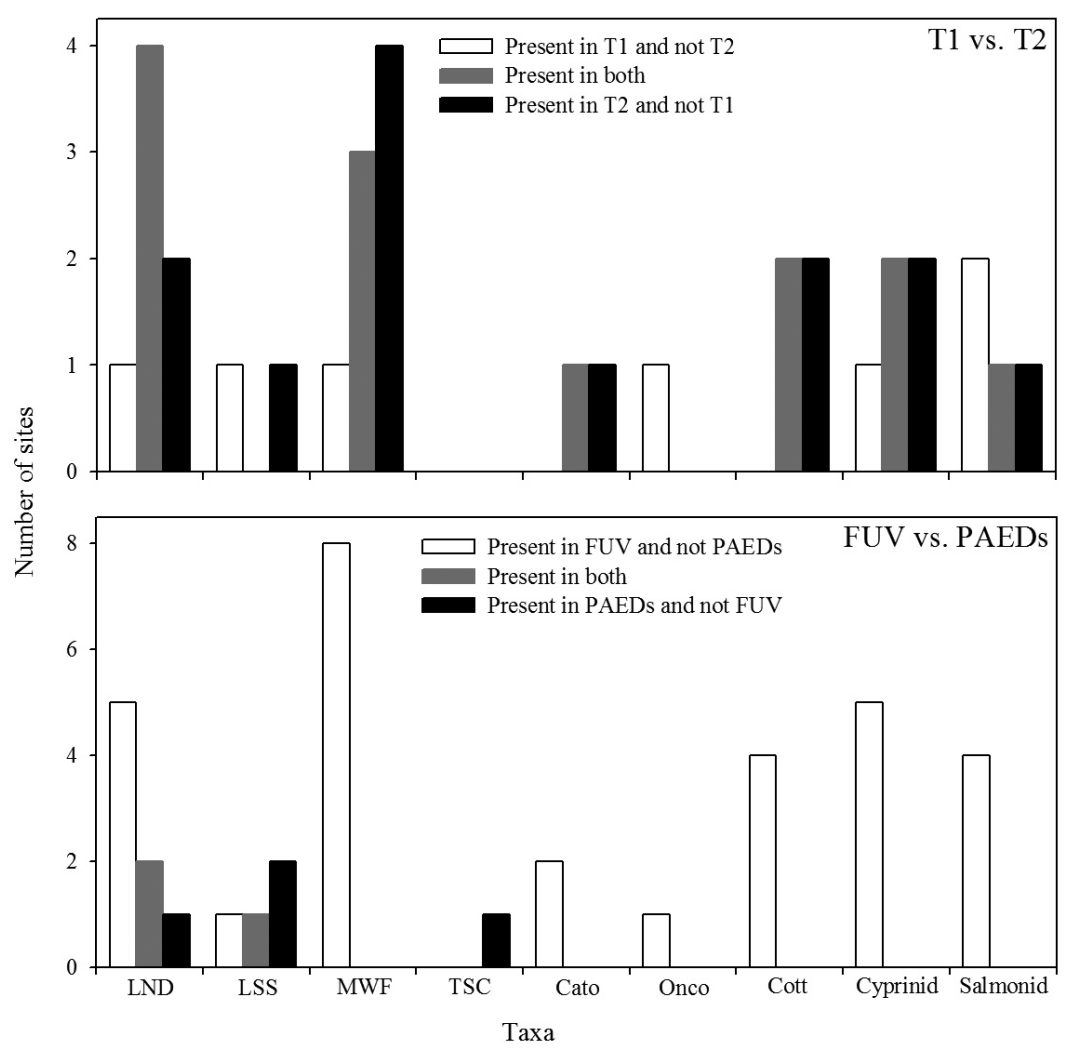

Fig. 2. Total number of sites where each taxon $(\mathrm{LND}=$ longnose dace, LSS $=$ largescale sucker, MWF $=$ mountain whitefish, TSC $=$ torrent sculpin, Cato = Catostomus spp., Onco = Oncorhynchus spp., Cott = Cottus spp., Cyprinid = Cyprinidae, Salmonid = Salmonidae) sampled from the Kootenai River, Idaho, was detected using fixed underwater videography (FUV) and prepositioned areal electrofishing devices (PAEDs) across 15 sites. The top panel compares occurrence estimates from time period one (T1, elapsed time between FUV and PAED deployment) and time period two (T2, elapsed time between PAED deployment and electrification). The bottom panel compares occurrence estimates between FUV and PAEDs.

\section{RESULTS}

Of the 28 sites sampled concurrently with PAEDs and FUV, 13 sites had unusable data due to malfunctioning PAEDs $(n=3)$, malfunctioning video cameras $(n=3)$, and visual obstructions (e.g., dense aquatic vegetation) in the video footage $(n=7)$. Accordingly, 15 sites were used in the analysis. Nine fish were sampled from 7 sites with PAEDs. All fish sampled by PAEDs were identified to species and included largescale sucker, longnose dace Rhinichthys cataractae, and torrent sculpin Cottus rhotheus. In total, 1086 fish were sampled across all 15 sites with FUV using the modified MaxN index. Fishes sampled with FUV were difficult to identify with confidence and were generally classified to genus or higher taxonomic levels, or as "unidentifiable."
Unidentified fishes comprised $53 \%$ of all FUV detections and $87 \%$ of the catch from the MaxN index. Eight of 9 identified taxa were sampled at least once with FUV, whereas PAEDs accounted for only 3 of 9 identified taxa across all sites (Fig. 2, lower panel).

Occurrence estimates for identified taxa were reasonably similar among video time periods (Fig. 2, upper panel) and variable among gear types (Fig. 2, lower panel). No salmonids were sampled by PAEDs; conversely, torrent sculpin were only sampled by PAEDs. Fixed underwater videography detected mountain whitefish at 8 sites. The species was undetected with PAEDs. In contrast, torrent sculpin, largescale sucker, and longnose dace were sampled at 4 different locations by PAEDs but were not identified using FUV at those sites (Fig. 2, lower panel). 


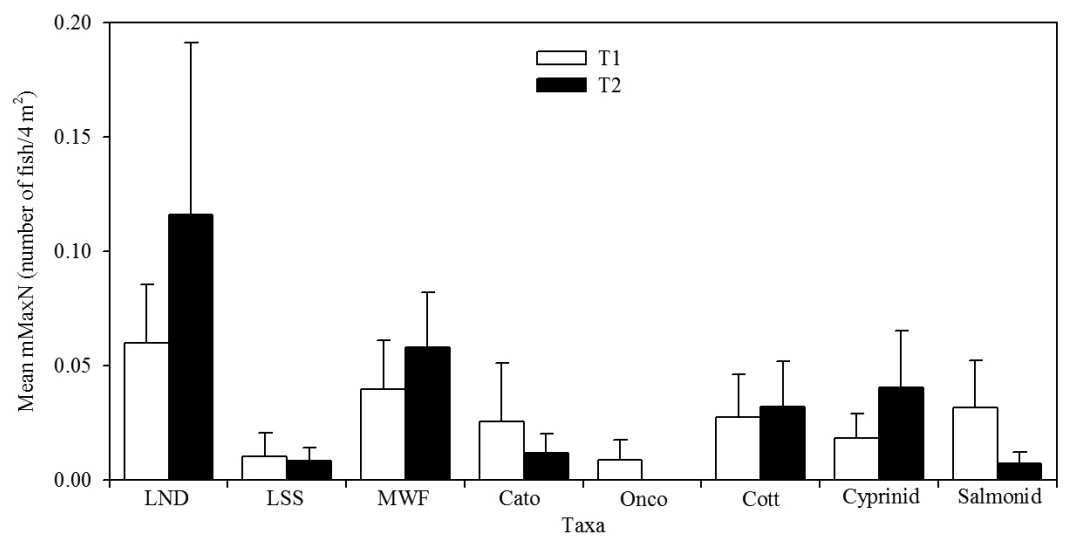

Fig. 3. Relative abundance $($ Mean $\mathrm{mMaxN})$ of identified taxa $(\mathrm{LND}=$ longnose dace, $\mathrm{LSS}=$ largescale sucker, $\mathrm{MWF}=$ mountain whitefish, Cato $=$ Catostomus spp., Onco $=$ Oncorhynchus spp., Cott $=$ Cottus spp., Cyprinid $=$ Cyprinidae, Salmonid $=$ Salmonidae) sampled using FUV from the Kootenai River, Idaho, across all sites $(n=15)$ for T1 ("baseline" footage; i.e., no electrode present in frame) and T2 ("set" footage; i.e., electrode present in video frame). Relative abundance estimates were calculated using a modified MaxN index, where MaxN was the maximum number of individuals within each minute of video footage. Mean MaxN (mMaxN) was calculated by taking the mean of MaxN across all minutes of reviewed FUV footage at each site. Mean mMaxN was estimated by computing the mean of mMaxN across all sites where a taxon was observed. Error bars represent \pm 1 standard error of the mean mMaxN.

Oncorhynchus spp. was the least observed taxon and was only observed during $\mathrm{Tl}$ at one site. Relative abundance estimates for identified fishes sampled with FUV were similar across $\mathrm{T} 1$ and $\mathrm{T} 2$ for most taxa except longnose dace, Catostomus spp., Oncorhynchus spp., and Cyprinidae (Fig. 3). A Wilcoxon signedrank test indicated no significant difference in relative abundance between the fish assemblage during $\mathrm{T} 1$ and $\mathrm{T} 2(P=0.74)$.

The elapsed time for each identified taxon to return to the sampling area following deployment of the PAED varied across sites (Table 1). All identified taxa exhibited at least one instance of failing to return to the sampling area or appearing in T2 without having been identified in T1. Only 2 of the 15 sites sampled displayed identical fish assemblages between T1 and T2. One additional site had identical assemblages between $\mathrm{T} 1$ and $\mathrm{T} 2$, although a torrent sculpin was sampled by electrofishing that was undetected by FUV. However, it is worth mentioning that FUV detected a Cottus spp. at that site that was likely a torrent sculpin because that was the only sculpin species we observed. Five sites displayed instances where the assemblages identified in $\mathrm{T} 1$ returned with at least one additional taxonomic group in T2. Average time for taxa identified in $\mathrm{Tl}$ to return to the sample area was $12.24 \mathrm{~min}$.

\section{Discussion}

The current study aims to evaluate the efficacy of 2 sampling gears for estimating the occurrence and relative abundance of riverine fishes. Across 15 sites, 9 taxa were collected from a relatively small sampling area. At any particular site, PAEDs and FUV sampled different taxa. All fishes collected with PAEDs were identified to species, whereas most fishes sampled by FUV were classified as "unidentifiable." Factors such as fish size, fish position, elapsed time spent by fish in the video frame, underwater visibility (e.g., turbidity, current velocity), and proficiency of the reviewer contribute to the ability to classify fish to lower taxonomic levels. The relative imprecision of identifying fish with FUV did not allow us to make direct comparisons between FUV data and PAED data. For example, Cottus spp. was detected with FUV at one site where torrent sculpin was sampled with PAEDs. Cyprinidae were sampled with FUV at several sites where longnose dace were sampled with PAEDs. Although the unidentified cyprinids were likely longnose dace, FUV could not provide conclusive identification.

At any particular sampling location, the occurrence estimates generated from data gathered by PAEDs and FUV varied. One reason that differences in occurrence were 
TABLE 1. Elapsed time $(\min )$ for each identified taxon (LND = longnose dace, LSS = largescale sucker, MWF = mountain whitefish, TSC $=$ torrent sculpin, Cato $=$ Catostomus spp., Onco $=$ Oncorhynchus spp., Cott $=$ Cottus spp., Cyprinid = Cyprinidae, Salmonid $=$ Salmonidae) to return to the video frame after deployment of a PAED (T2). Data are arranged by site in the Kootenai River, Idaho. Footage from fixed underwater videography (FUV) was subsampled in 5 -s or 20-s intervals following deployment of the electrofishing gear. The bottom 2 rows of the table represent means and standard errors (value in parentheses) calculated for each taxon where (1) all observations during T2 are considered (i.e., species additions were included in the mean calculation) and (2) only returning individuals are considered (i.e., values with asterisks were removed from the mean calculation).

\begin{tabular}{|c|c|c|c|c|c|c|c|c|c|}
\hline Site & LND & LSS & MWF & TSC & Cato & Onco & Cott & Cyprinid & Salmonid \\
\hline 1 & - & - & $\infty$ & - & - & $\infty$ & - & - & - \\
\hline 2 & - & a & - & - & - & - & - & - & - \\
\hline 3 & - & $+\infty$ & $23.58^{*}$ & - & 29.42 & - & - & - & - \\
\hline 4 & $10.00 *$ & - & - & - & $8.92 *$ & - & - & $10.25^{*}$ & 6.75 \\
\hline 5 & $4.67^{\dagger}$ & - & - & - & - & - & - & $\infty$ & - \\
\hline 6 & - & - & $2.92 *$ & - & - & - & - & - & - \\
\hline 7 & $11.50^{\dagger *}$ & - & 13.25 & - & - & - & $26.33^{*}$ & $7.33 *$ & - \\
\hline 8 & - & - & 2.42 & - & - & - & - & - & $9.83^{*}$ \\
\hline 9 & - & - & 18.58 & - & - & - & - & - & - \\
\hline 10 & - & a & - & - & - & - & 4.50 & - & - \\
\hline 11 & 6.50 & - & - & a & - & - & 18.50 & - & - \\
\hline 12 & $\infty$ & - & - & - & - & - & - & - & $\infty$ \\
\hline 13 & 11.17 & - & $10.17^{*}$ & - & - & - & - & - & - \\
\hline 14 & 21.25 & $22.17^{*}$ & $5.33^{*}$ & - & - & - & - & 0.25 & $\infty$ \\
\hline 15 & a & - & - & - & - & - & $8.92 *$ & 6.67 & - \\
\hline ALL & $10.85(2.35)$ & 22.17 & $10.89(3.06)$ & - & $19.17(10.25)$ & - & $14.56(4.89)$ & $6.13(2.11)$ & $8.29(1.54)$ \\
\hline Returning & $10.89(3.71)$ & - & $11.42(4.75)$ & - & 29.42 & - & $11.50(7.00)$ & $3.46(3.21)$ & 6.75 \\
\hline
\end{tabular}

†Sampled with PAED.

aNot observed during FUV processing but sampled with PAEDs.

* Taxon was not identified in the sampling frame prior to deployment of PAED (T1).

${ }^{\infty}$ Taxon was not identified in the sampling frame during T2.

observed may have been the amount of sampling time. The field sampling procedures required approximately $45 \mathrm{~min}$ to complete. The first 2 phases in the 3 -phase sampling procedure sampled for approximately $40 \mathrm{~min}$ with FUV. Following FUV data collection at a site, PAEDs sampled the same area for only 20 s. Nine individual fish were sampled by PAEDs across 15 sites, whereas FUV sampled over 1000 fish at the same locations. We would expect more observations of fishes with a longer sampling duration. However, the increase in observations with FUV comes with a substantial increase in processing time. On average, the video review procedure required approximately $2 \mathrm{~h}$ for $40 \mathrm{~min}$ of video footage. In contrast, data collected by PAEDs required minimal processing after the field procedure. Both PAEDs and FUV provide a measure of taxonomic occurrence, but the occurrence estimates generated from FUV necessitate laborious video processing in exchange for less precise data. Taxonomic classification of FUV samples was necessary for comparative purposes because all fish sampled by PAEDs were easily identified to species. Previous studies using FUV have employed other clas- sification systems, such as a guild approach (e.g., functional feeding group; Becker et al. 2010) or general body shape (Frezza et al. 2003). Selecting between PAEDs and FUVs is ultimately dependent on study objectives and the ability to resolve individual fishes to usable taxonomic classifications.

The likelihood of observing a fish by using PAEDs or FUV was low. The PAED set time used throughout this study likely had no effect on the number of fish sampled by PAEDs. Bain et al. (1985) were the first to describe the use of prepositioned electrofishing equipment. They noted that set times $>10 \mathrm{~min}$ appeared adequate and speculated that "very long set times seemed unnecessary." Results from our study indicated that a set time of at least 12 min reduced the effect of fright bias associated with deploying the gear. Our analysis of FUV footage indicated that fright bias was reduced $4 \mathrm{~min}$ after positioning the camera instream, further corroborating the hypothesis that set time had little influence on catch. The sparse observations of fish are likely due to discrepancies between movement dynamics of riverine fishes and the relatively small sampling area. Baxter (2002) found that movements of 
mountain whitefish in the Pacific Northwest varied from $0.2 \mathrm{~km}$ to $190.0 \mathrm{~km}$ throughout the study, regardless of fish size. Similarly, large-scale sucker movements varied from $17.2 \mathrm{~km}$ to nearly $300.0 \mathrm{~km}$ in the same study.

Despite the limitations of FUV, the sampling technique may be appropriate for some research questions in freshwater systems provided that the ability to identify fish satisfies project objectives. Video techniques would be especially useful for applications involving rare or imperiled fishes, which generally require special permits that limit fish handling procedures. For instance, Chaudoin et al. (2015) found that underwater videography outperformed above-water videography and in-person surveys for monitoring spawning activity of Devils Hole pupfish Cyprinodon diabolis. Ellender et al. (2012) determined that underwater videography accurately sampled imperiled fishes of South African headwater streams by comparing relative abundance estimates with those generated by 3 -pass electrofishing. Video techniques have also been used to validate or estimate catchability for other sampling gears. Grant et al. (2004) used underwater video techniques to estimate retention probability for walleye Sander vitreus in gill nets.

Small-scale processes like microhabitat use by fishes are difficult to capture, especially when sampling large river systems. Bain et al. (1985) suggested that PAEDs may be inefficient in fast, deep, turbid waters and that habitat specificity decreases as sample area and relative catch increase. Consequently, pilot studies may be warranted when using PAEDs to ensure that catch and habitat specificity meet study objectives. Similar limitations apply to the FUV methods used in this study, and visual obstructions (e.g., boulders, woody debris) further limit the ability to observe and identify fishes. For example, we could not use the data from one quarter of the sites sampled in this study due to visual obstruction. Many habitat rehabilitation programs incorporate the placement of large structures instream to enhance habitat complexity (Roni et al. 2002). Evaluating the response of fish to those habitat improvements using FUV may be ineffective given that cryptic fish species may be overlooked. Compared to electrofishing, underwater videography has known biases toward sampling simpler fish assemblages and small-bodied fish (Frezza et al. 2003). Smallbodied fishes composed the majority of individuals sampled by FUV in this study, but FUV samples provided increased taxonomic richness and diversity compared to PAED samples. These results are confounded to some extent due to the video review procedure and taxonomic "nestedness," but PAEDs sampled only one species at 6 sites where FUV sampled additional fishes belonging to different species, genera, and families.

Both PAEDs and FUV adequately reduce fright bias and provide fish occurrence and relative abundance estimates with regard to discrete microhabitats. Originally, we intended to process video footage by examining still frames in an attempt to decrease processing time. However, nearly all of the fishes sampled in this study were relatively small, and viewing video footage in real time allowed the reviewer to locate fishes by observing movements. If large-bodied fishes were sampled more frequently, the still-frame reviewing approach would substantially reduce processing time. The time spent reviewing and processing video footage may detect more taxa than would otherwise be sampled using PAEDs, but the time spent processing video footage could be allocated to sampling a broader spatial distribution with PAEDs. Therefore, we conclude that choosing between PAEDs and FUV for sampling riverine fishes requires a clear understanding of project objectives, and we recommend that careful consideration be given to the tradeoffs that exist between the gears.

\section{ACKNOWLEDGMENTS}

We thank T. Brauer and K. McBaine for their assistance with field and lab work and S. Banks at Midwest Lakes Electrofishing Systems for insight and guidance on constructing the PAEDs. We also thank Z. Klein and 2 anonymous reviewers for helpful comments on a previous edition of this manuscript. Funding for this project was provided by the Kootenai Tribe of Idaho and the Bonneville Power Administration. Additional support was provided by the U.S. Geological Survey, Idaho Cooperative Fish and Wildlife Research Unit. The unit is jointly sponsored by the U.S. Geological Survey, University of Idaho, Idaho Department of Fish and Game, and Wildlife 
Management Institute. This project was conducted under the University of Idaho Institutional Animal Care and Use Committee Protocol 2014-18. The use of trade, firm, or product names is for descriptive purposes only and does not imply endorsement by the U.S. Government.

\section{Literature Cited}

BaIn, M.B., J.T. FInN, AND H.E. Booke. 1985. A quantitative method for sampling riverine microhabitats by electrofishing. North American Journal of Fisheries Management 5:489-493.

BaXter, C.V. 2002. Fish movement and assemblage dynamics in a Pacific Northwest riverscape. Doctoral dissertation, Oregon State University, Corvallis, OR.

Becker, A.P., D. Cowley, And A.K. Whitfield. 2010. Use of remote underwater video to record littoral habitat use by fish within a temporarily closed South African estuary. Journal of Experimental Marine Biology and Ecology 391:161-168.

Bernhardt, E.S., M.A. Palmer, J.D. Allan, G. Alexander, K. Barnas, S. Brooks, J. Carr, S. Clayton, C. Dahm, and J. Follstad-Shah, ET AL. 2005. Synthesizing U.S. river restoration efforts. Science 308: 636-637.

Bonar, S.A., W.A. Hubert, and D.W. Willis, editors. 2009. Standard methods for sampling North American freshwater fishes. American Fisheries Society, Bethesda, MA.

BoveE, K.D. 1982. A guide to stream habitat analysis using the instream flow incremental methodology. U.S. Fish and Wildlife Service FWS/OBS-82/26, Washington, DC.

BozeK, M.A., AND F.J. Rahel. 1991. Comparison of streamside visual counts to electrofishing estimates of Colorado River cutthroat trout fry and adults. North American Journal of Fisheries Management 11:38-42.

Chaudoin, A.L., O.G. Feuerbacher, S.A. Bonar, and P.J. BARRETT. 2015. Underwater videography outperforms above-water videography and in-person surveys for monitoring the spawning of Devils Hole pupfish. North American Journal of Fisheries Management 35:1252-1262.

Curry, R.A., R.M. Hughes, M.E. McMaster, and D.J. ZAFFT. 2009. Coldwater fish in rivers. Pages 139-158 in S.A. Bonar, W.A. Hubert, and D.W. Willis, editors, Standard methods for sampling North American freshwater fishes. American Fisheries Society, Bethesda, MD.

Daumalter, D.C., S.J. Wenger, and P. Gardner. 2014. The role of complexity in habitat use and selection by stream fishes in a Snake River basin tributary. Transactions of the American Fisheries Society 143:1177-1187.

Dudgeon, D., A.H. Arthington, M.O. Gessner, Z.-I. Kawabata, D.J. Knowler, C. LÉvêque, R.J. Naiman, A.-H. Prieur-Richard, D. Soto, M.L.J. Stiassny, AND C.A. Sullivan. 2006. Freshwater biodiversity: importance, threats, status and conservation challenges. Biological Reviews 81:163-182.

Ebner, B., R. Clear, S. Godschalx, and M. Beitzel. 2009. In-stream behaviour of threatened fishes and their food organisms based on remote video monitoring. Aquatic Ecology 43:569-576.

Ebner, B.C., and D.L. Morgan. 2013. Using remote underwater video to estimate freshwater fish species richness. Journal of Fish Biology 82:1592-1612.

Ellender, B.R., A. Becker, O.L.F. WeYl, and E.R. SWARTZ. 2012. Underwater video analysis as a nondestructive alternative to electrofishing for sampling imperiled headwater stream fishes. Aquatic Conservation: Marine and Freshwater Ecosystems 22: $58-65$.

Ellis, D.M., And E.E. DeMartini. 1995. Evaluation of a video camera technique for indexing abundances of juvenile pink snapper, Pristipomoides filamentosus, and other Hawaiian insular shelf fishes. Fishery Bulletin 93:67-77.

Fausch, K.D., and R.J. White. 1981. Competition between brook trout (Salvelinus fontinalis) and brown trout (Salmo trutta) for position in a Michigan stream. Canadian Journal of Fisheries and Aquatic Sciences 38:1220-1227.

Fisher, W.L., M.A. Bozek, J.C. Vokoun, and R.B. JaCobSON. 2012. Freshwater aquatic habitat measurements. Pages 101-161 in A.V. Zale, D.L. Parrish, and T.M. Sutton, editors, Fisheries techniques. 3rd edition. American Fisheries Society, Bethesda, MD.

Frezza, T.L., L.M. CarL, and S.M. Reid. 2003. Evaluation of a portable underwater video camera to study fish communities in two Lake Ontario tributaries. Journal of Freshwater Ecology 18:269-276.

GORMAN, O.T., AND J.R. KARR. 1978. Habitat structure and stream fish communities. Ecology 59:507-515.

Grant, G.C., P. Radomski, and C.S. Anderson. 2004. Using underwater video to directly estimate gear selectivity: the retention probability for walleye (Sander vitreus) in gill nets. Canadian Journal of Fisheries and Aquatic Sciences 61:168-174.

GRIFFITH, J.S. 1981. Estimation of the age-frequency distribution of stream-dwelling trout by underwater observation. Progressive Fish Culturist 43:51-53.

Hankin, D.J., AND G.H. ReEves. 1988. Estimating total fish abundance and total habitat area in small streams based on visual estimation methods. Canadian Journal of Fisheries and Aquatic Sciences 45: 834-844.

Hannah, R.W., and M.T.O. Blume. 2012. Tests of an experimental unbaited video lander as a marine fish survey tool for high-relief deepwater rocky reefs. Journal of Experimental Marine Biology and Ecology 430-431:1-9.

Harvey, E.S., M. Cappo, J.J. Butler, N. Hall, and G.A. KENDRICK. 2007. Bait attraction affects the performance of remote underwater video stations in assessment of demersal fish community structure. Marine Ecology Progress Series 350:245-254.

Kane, A.S., J.D. Salierno, G.T. Gipson, T.C.A. Molteno, AND C. HunTER. 2004. A video-based movement analysis system to quantify behavioral stress responses of fish. Water Research 38:3993-4001.

KNudson, K. 1994. Water quality status report, Kootenay (Kootenai) River Basin, British Columbia, Montana, and Idaho. The Kootenai River Network, Inc., Libby, MT, and Ecological Resource Consulting, Helena, MT.

Kondolf, G.M., AND E.R. Micheli. 1995. Evaluating stream restoration projects. Environmental Management 19:1-15. 
[KTOI] Kootenai Tribe of Idaho. 2009. Kootenai River habitat restoration master plan. Kootenai Tribe of Idaho Technical Report, Bonners Ferry, ID.

Nilsson, C., C.A. Reidy, M. Dynesius, and C. Revenga. 2005. Fragmentation and flow regulation of the world's large river systems. Science 308:405-408.

Palmer, M.A., E.S. Bernhardt, J.D. Allan, P.S. Lake, G. Alexander, S. Brooks, J. Carr, S. Clayton, C.N. Dahm, J. Follstad Shah, ET AL. 2005. Standards for ecologically successful river restoration. Journal of Applied Ecology 42:208-217.

Peterson, J.T., N.P. Banish, and R.F. Thurow. 2005. Are block nets necessary?: movement of stream-dwelling salmonids in response to three common survey methods. North American Journal of Fisheries Management 25:732-743.

Quist, M.C., F.J. Rahel, and W.A. Hubert. 2005. Hierarchical faunal filters: an approach to assessing effects of habitat and nonnative species on native fishes. Ecology of Freshwater Fish 14:24-39.

Reynolds, J.B., And L. Kolz. 2012. Electrofishing. Pages 305-361 in A.V. Zale, D.L. Parrish, and T.M. Sutton, editors, Fisheries techniques. 3rd edition. American Fisheries Society, Bethesda, MD.

Ricciardi, A., AND J.B. Rasmussen. 1999. Extinction rates of North American freshwater fauna. Conservation Biology 13:1220-1222

Roni, P., T.J. Beechie, R.E. Bilby, F.E. Leonetti, M.M. Pollock, AND G.R. PESs. 2002. A review of stream restoration techniques and a hierarchical strategy for prioritizing restoration in Pacific Northwest watersheds. North American Journal of Fisheries Management 22:1-20.

Roni, P., K. Hanson, and T. BeEchie. 2008. Global review of the physical and biological effectiveness of stream habitat rehabilitation techniques. North American Journal of Fisheries Management 28:856-890.

Rosenfeld, J. 2003. Assessing the habitat requirements of stream fishes: an overview and evaluation of different approaches. Transactions of the American Fisheries Society 132:953-968.

Ross, S.T. 1986. Resource partitioning in fish assemblages: a review of field studies. Copeia 1986:352-388.

Smith, C.D., M.C. Quist, and R.S. Hardy. 2016. Fish assemblage structure and habitat association in a large western river system. River Research and Applications 32:622-638.

Stobart, B., J.A. García-Charton, C. Espejo, E. Rochel, R. Goñi, O. Reñones, A. Herrero, R. Crec'hriou,
S. Polti, C. Marcos, et AL. 2007. A baited underwater video technique to assess shallow-water Mediterranean fish assemblages: methodological evaluation. Journal of Experimental Marine Biology and Ecology 345:158-174.

Stoner, A.W., B.J. Laurel, AND T.P. Hurst. 2008. Using a baited camera to assess relative abundance of juvenile Pacific cod: field and laboratory trials. Journal of Experimental Marine Biology and Ecology 354: 202-211.

SuZuki, K., T. TaKagi, and T. Hiraishi. 2003. Video analysis of fish schooling behavior in finite space using a mathematical model. Fisheries Research 60:3-10.

Thurow, R.F., C.A. Dolloff, and J.E. Marsden. 2012. Visual observation of fishes and aquatic habitat. Pages 781-817 in A.V. Zale, D.L. Parrish, and T.M. Sutton, editors, Fisheries techniques. 3rd edition. American Fisheries Society, Bethesda, MD.

Watkins, C.J., B.S. Stevens, M.C. Quist, B.B. Shepard, and S.C. IreLand. 2015. Patterns of fish assemblage structure and habitat use among main- and sidechannel environments in the lower Kootenai River, Idaho. Transactions of the American Fisheries Society 144:1340-1355.

Watson, D.L., E.S. Harvey, M.J. Anderson, and G.A. KENDRICK. 2005. A comparison of temperate reef fish assemblages recorded by three underwater stereovideo techniques. Marine Biology 148:415-425.

Willis, T.J., AND R.C. BABCOCK. 2000. A baited underwater video system for the determination of relative density of carnivorous reef fish. Marine and Freshwater Research 51:755-763.

Wilson, K.L., M.S. Allen, R.N.M. Ahrens, and M.D. NETHERLand. 2015. Use of underwater video to assess freshwater fish populations in dense submersed aquatic vegetation. Marine and Freshwater Research 66:10-22.

Woods, P.F. 1982. Annual nutrient loadings, primary productivity, and trophic state of Lake Koocanusa, Montana and British Columbia, 1972-80. U.S. Geological Survey Professional Paper 1283, Reston, VA.

Received 21 February 2017

Revised 25 September 2017

Accepted 19 December 2017

Published online 19 April 2018 